Trinity University

Digital Commons @ Trinity

School of Business Faculty Research

School of Business

Spring 2022

\title{
Are Auditors' Reliance on Conclusions from Data Analytics Impacted By Different Data Analytic Inputs?
}

Jared Koreff

Trinity University, jkoreff@trinity.edu

Follow this and additional works at: https://digitalcommons.trinity.edu/busadmin_faculty

Part of the Business Administration, Management, and Operations Commons

\section{Repository Citation}

Koreff, J. (2022). Are auditors' reliance on conclusions from data analytics impacted by different data analytic inputs? Journal of Information Systems, 36(1), 19-37. http://doi.org/10.2308/ISYS-19-051

This Post-Print is brought to you for free and open access by the School of Business at Digital Commons @ Trinity. It has been accepted for inclusion in School of Business Faculty Research by an authorized administrator of Digital Commons@ Trinity. For more information, please contact jcostanz@trinity.edu. 


\title{
Are auditors' reliance on conclusions from data analytics impacted by different data analytic inputs?
}

\author{
JARED KOREFF \\ TRINITY UNIVERSITY \\ JKOREFF@TRINITY.EDU
}

Running head: Auditors' reliance on data analytics using different inputs

Acknowledgements: This study is based on my dissertation. I thank my dissertation committee of Vicky Arnold (co-chair), Steve Sutton (co-chair), Lisa Baudot and Joe Brazel (external member) as well as David Wood (editor), two anonymous reviewers, Kazeem Akinyele, Helen Brown-Liburd, Joyce Cheng, Jorge Colazo, Charlie Cullinan, Sean Dennis, Amy Donnelly, Chris Earley, Severin Grabski, Hussein Issa, Ethan Lamothe, Bill Messier, Martin Ndicu, Wioleta Olczak, Steve Perreault, Julie Persellin, Robert Scherer, Andrea Stapleton, Jay Thibodeau, Cristina Thomas, Greg Trompeter, Marcia Weidenmier Watson, Deli Yang, Diana Young, workshop participants at Iowa State University, Ithaca College, Northern Arizona University, Rutgers Camden, Trinity University, UMASS Lowell, University of North Carolina Greensboro, University of Wisconsin La Crosse and participants at the 2018 ABO midyear meeting and 2019 AIS / SET midyear meeting for their helpful comments and suggestions on earlier drafts of this paper. 


\title{
Are auditors' reliance on conclusions from data analytics impacted by different data analytic inputs?
}

\begin{abstract}
Global stakeholders have expressed interest in increasing the use of data analytics throughout the audit process. While data analytics offer great promise in identifying audit-relevant information, auditors may not uniformly incorporate this information into their decision making. This study examines whether conclusions from two data analytic inputs, the type of data analytical model (anomaly vs. predictive) and type of data analyzed (financial vs. nonfinancial), result in different auditors' decisions. Findings suggest that conclusions from data analytical models and data analyzed jointly impact budgeted audit hours. Specifically, when financial data is analyzed auditors increase budgeted audit hours more when predictive models are used than when anomaly models are used. The opposite occurs when nonfinancial data is analyzed, auditors increase budgeted audit hours more when anomaly models are used compared to predictive models. These findings provide initial evidence that data analytics with different inputs do not uniformly impact auditors' judgments.
\end{abstract}

Key Words: Auditor judgment, Data analytics, Nonfinancial measures, Predictive analytics, Text mining

JEL Classifications: M41, M42, C53, C55

Data Availability: Data used in this study is available upon request 


\section{INTRODUCTION}

Advances in technology have enabled auditors to increase their use of data analytics (AICPA 2015a; Coffey 2015; Ernst and Young 2015a; Deloitte 2018a). These advances have facilitated the development of more sophisticated data analytical tools that hold great promise for implementation in the audit process. These tools extend auditors' capabilities in several ways, including robotic process automation (Cooper, Holderness, Sorensen, and Wood 2019; Cooper, Holderness, Sorensen, and Wood 2021), population testing, and identifying all outliers based on established criteria (Jans, Alles, and Vasarhelyi 2014; Kogan, Alles, Vasarhelyi, and Wu 2014; Titera 2013; Richins, Stapleton, Stratopoulos, and Wong 2017; Huerta and Jensen 2017). Data analytics can also be used for predictive modeling (Statistical Analysis System [SAS] Institute 2014; Krahel and Titera 2015) and analysis of non-traditional unstructured data, such as text and videos (Holton 2009; Warren, Moffitt, and Byrnes 2015; Yoon, Hoogduin, and Zhang 2015; Vasarhelyi, Kogan, and Tuttle 2015; Loughran and Mcdonald 2016; PCAOB 2016; IAASB 2017; PCAOB 2018). Enhanced capabilities of data analytics have caused global stakeholders to express interest in increasing the use of data analytics throughout the audit process (PCAOB 2018; Coffey 2015; IAASB 2017; AICPA 2015b; Appelbaum, Kogan, and Vasarhelyi 2017; AICPA 2017). Data analytics hold the potential to fundamentally change the audit process by greatly reducing the distinction between analytical procedures and substantive testing (Jans et al. 2014; Kogan et al. 2014).

Data analytics can be viewed as an outgrowth of analytical procedures (Appelbaum et al. 2017). Yet auditors may be averse to using certain data analytics, given their preference for simpler analytical procedures (Ameen and Strawser 1994; Trompeter and Wright 2010). Further, the PCAOB has identified deficiencies in auditors' use of analytical procedures (PCAOB 2007a; 
PCAOB 2007b; PCAOB 2008; PCAOB 2013; PCAOB 2014), suggesting that auditors use analytical procedures improperly (Messier, Simon, and Smith 2013). These improper uses may persist when data analytics are used. Incorporating data analytics into the audit process will allow auditors to reallocate time from labor-intensive tasks to judgment-intensive tasks (AICPA 2015a; Brown-Liburd, Issa, and Lombardi 2015). Despite the increased capabilities of data analytics, if auditors do not use these tools properly, they may miss the opportunity to improve the audit process and audit quality (PCAOB 2016; PCAOB 2018). For example, the benefits from data analytics will go unrealized if auditors are overwhelmed with too much information (Issa and Kogan 2014; Brown-Liburd et al. 2015). Yet extant empirical research on how data analytics influence auditors' judgments is limited to examining data analytic outputs. Specifically, prior data analytics research on auditors' judgments is confined to that of A. Rose, J. Rose, Sanderson, and Thibodeau (2017), who demonstrate that auditors are not always effective at identifying patterns in data analytic visualizations. ${ }^{1}$ Therefore, the purpose of this study is to provide an initial examination of whether data analytic inputs, specifically the type of data analytical model used and the type of data analyzed, influence auditors' decisions.

According to cognitive fit theory, auditors will have greater cognitive fit with data analytics if they use analyses they are familiar with because cognitive fit increases with experience (Goodhue and Thompson 1995; Arnold and Sutton 1998; Dunn and Grabski 2001). Cognitive fit occurs when there is congruence between the underlying method or process used by a decision maker and a decision aid tool (Vessey and Galletta 1991; Al-Natour et al. 2008). While data analytics can perform new analyses of new types of data, auditors will experience

\footnotetext{
${ }^{1}$ Several working papers examine other aspects of analytics: those of Austin, Carpenter, Christ, and Nielsen 2019; Emett, Kaplan, Mauldin and Pickerd 2019; Ballou, Grenier, and Reffett 2019; Barr-Pulliam, Brazel, McCallen, and Walker 2020; A. Rose, J. Rose, Sanderson, Thibodeau, and Rotaru 2019; Koreff and Perreault 2020.
} 
different levels of cognitive fit using the analytics based on the inputs (i.e., method or process) used. Anomaly models perform a distributional (bell curve) analysis to identify outliers (SAS 2014), and auditors use basic versions of these models when performing analytical procedures (Cohen, Krishnamoorthy, and Wright 2000; Asare, Wright, and Trompeter 2000; Glover, Prawitt, and Wilks 2005; Brazel, Jones, and Zimbelman 2009). Predictive models analyze patterns of previously identified issues and compare them with current patterns (Kuenkaikaew and Vasarhelyi 2013). Although there is a lack of research examining auditors' use of predictive models, practitioner sources state that these models are used (KPMG 2012; Deloitte 2013; Ernst and Young 2013; Sinclair 2015; PwC 2015; Agnew 2016b; Deloitte 2018b). Given the focus of prior academic research on anomaly models and practitioner sources discussing predictive analytics in practice, auditors' experience using predictive and anomaly models is not expected to differ, making it critical to consider a second input: the type of data analyzed by these models.

Data analytical models can analyze nonfinancial data, creating opportunities to identify audit-relevant information from new sources (Warren et al. 2015; Vasarhelyi et al. 2015; PCAOB 2016). Predictive models focus on analyzing financial data (Dechow, Ge, Larson, and Sloan 2011; Sinclair 2015; Perols, Bowen, Zimmermann, and Samba 2017), whereas analyses using anomaly models are mixed between financial and nonfinancial data (Glover et al. 2005; Cho, Roberts, and Patten 2010; Hobson, Mayew, and Venkatachalam 2012; Brazel, Jones, and Prawitt 2014). Therefore, I expect auditors' judgments to be influenced more by conclusions drawn from financial data analyzed by predictive models than those analyzed by anomaly models, and more by conclusions drawn from nonfinancial data analyzed by anomaly models than those analyzed by predictive models. 
An experiment was conducted to examine the impact of the type of data analytical models used (predictive vs. anomaly) and type of data analyzed (financial vs. nonfinancial) on 98 auditors' decisions. A central data analytics group presented participants with unusual activity identified by either anomaly or predictive data analytical models that analyzed either financial data (journal entries) or nonfinancial data (e-mail language). The results of this study show that different data analytic inputs do not always result in uniform decision-making. Specifically, the type of data analytical model used and the type of data analyzed have a differential impact on auditors' decisions to increase budgeted audit hours. Auditors increase budgeted audit hours more in response to conclusions from financial data analyzed by predictive models than those analyzed by anomaly models. The opposite is true for analysis of nonfinancial data: auditors increase budgeted hours more in response to conclusions from nonfinancial data analyzed by anomaly models than those analyzed by predictive models. Thus, auditors' cognitive fit from using different analyses results in different budgeted audit hours when viewing conclusions from different data analytic inputs (models and data). In follow-up interviews with 26 participants from the experiment, interviewees confirmed the tendency of predictive analytics to analyze financial information, whereas anomaly models are more likely to analyze both types of data.

This study provides four contributions to the literature on the impact of data analytics on auditors' decisions. To my knowledge, this is the first study to empirically demonstrate that different data analytic inputs, the type of model used and the type of data analyzed differentially influence auditors' judgments. Although data analytics may identify audit-relevant information, this study shows that presenting auditors with findings from the analytics may result in different judgments, creating a potential missed opportunity to improve audit quality. Yet firms can capitalize on these differences to enhance auditor effort in response to identified audit risks by 
simply tailoring the type of data analyzed by using different data analytical models. Second, this study provides initial evidence that predictive analytics influence auditors' decision-making. Third, this study contributes to cognitive fit theory by extending cognitive fit to a new setting: auditors' decisions using data analytics. Finally, alongside providing more opportunities to analyze unstructured data (Huerta and Jensen 2017), this study extends prior research on auditors' decisions using nonfinancial data to unstructured data (Trompeter and Wright 2010; Brazel et al. 2014).

\section{Data Analytics}

\section{BACKGROUND}

Technology is constantly advancing (Hirsch 2015) and is causing significant changes in businesses (Eulerich and Kalinichenko 2018). As technology advances, the capability of, and interest in, data analytics and analysis of unprecedentedly large data sets in the accounting literature has expanded (Alles and Gray 2015). In line with this expansion of analytical capabilities, the AICPA's Assurance Services Executive Committee (ASEC) has developed an "Audit Data Analytics Guide" to replace the Analytical Procedures Guide, suggesting that data analytics are an outgrowth and expansion of analytical procedures (AICPA 2015b; Appelbaum et al. 2017; AICPA 2017). Thus, analytical procedures are a predecessor and subset of data analytics. ${ }^{2}$ Similar to the AICPA's ASEC committee, the Data Analytics Working Group (DAWG) has established the IAASB (IAASB 2017). The primary objectives of the DAWG are to determine how to effectively use data analytics to enhance audit quality and to consider revising international standards to enable the use of data analytics in the audit process (IAASB

\footnotetext{
${ }^{2}$ Audit data analytics are defined as "the science and art of discovering and analyzing patterns, identifying anomalies, and extracting other useful information in data underlying or related to the subject matter of an audit through analysis, modeling, and visualization for the purpose of planning or performing the audit" (AICPA 2017).
} 
2017). Finally, the PCAOB's most recent strategic plan states that PCAOB oversight will not impede auditors' use of data analytics that enhance audit quality (PCAOB 2018).

The availability of data analytics does not guarantee that firms will incorporate these tools in the audit process, nor that identification of audit-relevant information by data analytics will influence auditors' decisions. The mere availability of decision-aiding tools, such as data analytics, is insufficient to improve decision-making because decision makers may not use these tools (F. Davis, Bagozzi, and Washaw 1989; Messier 1995; Venkatesh, Morris, G. Davis, and F. Davis 2003). For example, decision makers may resist using new technologies and features of new technologies (Loraas and Wolfe 2006; Diaz and Loraas 2010; Loraas and Diaz 2011), even when the tool has always provided accurate information (Sutton, Young and McKenzie 1995).

While the focus of this study is on auditors' decisions using data analytics, given the limited prior empirical examination, insights on this topic can be obtained from examining auditors' use of data analytics predecessor: analytical procedures (see Messier et al. 2013 for a review). Analytical procedures influence auditors' decision-making (Asare et al. 2000; Glover et al. 2005; O’Donnell and Schultz 2003; Brewster 2011; Luippold and Kida 2012). Yet PCAOB inspections have identified deficiencies in auditors' use of analytical procedures (PCAOB 2007a; PCAOB 2007b; PCAOB 2008) (e.g., insufficiently investigating unexpected fluctuations [PCAOB 2008; PCAOB 2014]).

Although prior research has focused on auditors' use of analytical procedures using financial measures (Asare et al. 2000; Knapp and Knapp 2001; O’Donnell and Schultz 2005), nonfinancial measures have been examined as well (Cohen et al. 2000; Brazel et al. 2009; Brazel et al. 2014). These nonfinancial measures include employee headcount, production space, warehouse space, trading volume, retail space, economic conditions, industry changes, growth, 
and market penetration (Amir and Lev 1996; Cohen et al. 2000; Brazel et al. 2009; Brazel et al. 2014). Nonfinancial measures can facilitate the development of more precise expectations (Trompeter and Wright 2010) and enhance decision-making (Messier et al. 2013).

\section{Data Analytical Models}

The two types of data analytical models examined in this study are anomaly models and predictive models. Anomaly models use a bell curve analysis to identify outliers (SAS 2014). Prior research on analytical procedures has focused on similar, albeit less sophisticated, anomaly models (Cohen et al. 2000; Glover et al. 2005; Brewster 2011), suggesting that auditors are experienced with the mental processes required to incorporate the results from these models into their decision-making. Anomaly models can identify data exhibiting abnormally high or low amounts compared with a peer group (DHHS 2014; SAS 2014), and changes from prior periods (Cohen et al. 2000; Brewster 2011). Although anomaly models can identify emerging events, a limitation of these models is that they are prone to identifying false positives (SAS 2014).

Predictive models "analyze patterns and past performance in relationships to a particular desired outcome to predict the probability of that outcome" (SAS 2012, 2). As stated in a report to Congress, "A single predictive model is often as effective as multiple non-predictive models" (DHHS 2015, 9). Predictive analytics can identify patterns with previously unexamined variables to identify otherwise undetectable patterns indicative of a misstatement risk. This allows models to adapt to new events and independently develop new models (Kuenkaikaew and Vasarhelyi 2013). Predictive models can aid in fraud detection (Perols et al. 2017; Grover et al. 2018). These models demonstrate that material misstatements are more likely to be filed subsequent to a reversal of abnormally high accruals (Dechow et al. 2011). Predictive models can also facilitate asset valuations as well as forecasting cash flows, revenue, and stock performance (Sinclair 
2015; Schneider, Dai, Janvrin, Ajayi, and Raschke 2015; Agnew 2016a). Predictive models are more powerful and less prone to identifying false positives than other analytics, such as anomaly models (SAS 2014; DHHS 2015). However, these models are confined to identifying patterns with previous events (SAS 2014) and cannot identify patterns associated with emerging risks.

\section{THEORY AND HYPOTHESIS DEVELOPMENT}

\section{Cognitive Fit}

Cognitive fit is the congruence of the cognitive process used by a decision maker and the underlying decision strategy of a tool used to facilitate decision-making (Vessey and Galletta 1991; Arnold and Sutton 1998; Al-Natour et al. 2008). The Theory of Technology Dominance (TTD) identifies factors influencing implementation of a technology enabled tool (Triki and Weisner 2014), such as data analytics (Brown-Liburd et al. 2015). TTD states that a user's reliance on a decision-aiding tool is a function of cognitive fit (as well as task experience, task complexity, and decision aid familiarity) (Arnold and Sutton 1998). Thus, according to TTD, an increase in cognitive fit will increase a decision maker's reliance on a decision-aiding tool. ${ }^{3}$ TTD defines cognitive fit as "the degree to which the cognitive processes used with the decision aid to complete or solve a task match the cognitive processes normally used by an experienced decision maker" (Arnold and Sutton 1998, 180).

A lack of cognitive fit between the decision maker and the decision-aiding tool requires the decision maker to mentally transform the information presented into a useful format. Mental transformation often causes the decision maker to discount or disregard information (Nisbett and

\footnotetext{
${ }^{3}$ I opted against examining the influence of task experience, task complexity or familiarity with the decision-aiding tool on auditors' decision-making because of concerns related to collecting appropriate data and using effective manipulations. Prior experience adjusting a budget was measured and did not differ across conditions. While prior cognitive fit research has focused on cognitive fit arising from different presentation formats (Vessey and Galletta 1991), this study focuses on cognitive fit arising from users' experience with the underlying process used by a decision-aiding tool (Goodhue and Thompson 1995; Arnold and Sutton 1998; Dunn and Grabski 2001).
} 
Ross 1980), such as red flags identified (Masselli et al. 2002), ultimately impairing performance (Agarwal et al. 1996). When a decision maker is not required to mentally tranform information, it is less mentally taxing, which induces use of the information (Hampton 2005). Individuals seek to minimize cognitive effort (Triki and Weisner 2014), so they will forego mental effort at the expense of decision quality (Todd and Benbasat 1992).

Because greater experience using a particular analysis increases cognitive fit (Goodhue and Thompson 1995; Dunn and Grabski 2001), auditors will exhibit greater cognitive fit with conclusions drawn from data analytics using familiar analyses. Even when not directly conducting analysis, decision makers' cognitive fit will increase when they have prior experience using the analysis employed by the tool. Greater cognitive fit between the decision maker and the information provided makes it easier for the decision maker to acquire information (Messier 1995 ) and, in turn, engage in quicker and more accurate problem solving (Vessey 1991; Vessey and Galletta 1991; Noga and Arnold 2002; Dunn, Gerrad, and Grabski 2017; Kelton et al. 2010; Tuttle and Kershaw 1998). While conclusions drawn from different analytics may be similar, or even identical, the underlying process used to arrive at that conclusion can vary significantly, and as a result, affect cognitive fit. Therefore, auditors will experience higher levels of cognitive fit when viewing conclusions from data analytics that use a familiar process.

Auditors are experienced with the underlying process used by anomaly models because analytical procedures tend to represent less sophisticated versions of these models (Asare et al. 2000; Cohen et al. 2000; Glover et al. 2005; Brewster 2011). Additionally, practitioner sources discuss the use of predictive models (PwC 2015; KPMG 2012; Deloitte 2018b; EY 2013; Sinclair 2015; Agnew 2016a; AICPA 2017). Therefore, auditors are expected to have comparable experience with the underlying processes of these models and the level of cognitive 
fit experienced will not differ. Comparable experience with different models makes it critical to consider the impact of a second input, the type of data analyzed, on decision-making.

\section{Type of Data Analyzed}

Although the two types of models previously discussed are expected to be used at similar levels, extant literature shows that predictive models are typically used to analyze financial data, whereas anomaly models are mixed. Anomaly models can make comparisons of nonfinancial data with financial data (Brazel et al. 2009; Brazel et al. 2014; Brazel and Schmidt 2019) and with a peer group to identify high amounts of certain language (Cho et al. 2010; Li 2010; Humpherys et al. 2011; Davis and Tama-Sweet 2012; Hobson et al. 2012; Warren et al. 2015). These comparisons suggest that anomaly models more commonly analyze nonfinancial data than predictive models do, giving rise to higher cognitive fit. Accordingly, conclusions from nonfinancial data will have a greater impact on auditors' decisions when analyzed by anomaly, as compared with predictive, models.

Unlike in the case of nonfinancial data, when considering the analysis of financial data, predictive models focus almost exclusively on analyzing financial data (Dechow et al. 2011; Sinclair 2015; Agnew 2016b; Perols et al. 2017; Nallareddy and Ogneva 2017), whereas anomaly models analyze financial and nonfinancial data (Cohen et al. 2000; Glover et al. 2005; Cho et al. 2010; Hobson et al. 2012; Brazel et al. 2014). Predictive models in accounting tend to focus on financial data such as accruals, financial performance, and earnings dispersion (Dechow et al. 2011; Sinclair 2015; Agnew 2016b; Perols et al. 2017; Nallareddy and Ogneva 2017). Therefore, when analyzing financial data, auditors will have more experience, and greater cognitive fit using predictive models than using anomaly models. Accordingly, conclusions from 
financial data will have a greater impact on auditors' decisions when analyzed by predictive, as compared with anomaly, models.

Auditors are expected to have comparable experience using anomaly and predictive models. Yet auditors will experience greater cognitive fit and their judgments will be influenced more by conclusions from predictive analytics that analyze financial data as compared with nonfinancial data. Alternatively, there is no significant distinction in the cognitive fit expected for anomaly models based on the data analyzed. Therefore, I expect auditors to rely more on conclusions from analyzing financial data using predictive analytics than those using anomaly analytics, and more on conclusions from analyzing nonfinancial data using anomaly analytics than those using predictive analytics.

Hypothesis: Auditors will rely more on conclusions from predictive (anomaly) data analytic models of financial data than those from anomaly (predictive) data analytic models of financial (nonfinancial) data.

\section{METHODS - EXPERIMENT}

\section{Participants}

Using an online survey, I collected and analyzed responses from 98 external financial statement auditors identified through professional connections. ${ }^{4}$ Participants averaged 9.0 years of audit experience. Thirty-seven participants (38\%) had the title of manager, director, or partner. National or international firms employed sixty participants (61\%). Seventy-six participants

\footnotetext{
${ }^{4}$ To incentivize participants, upon completion of the survey, they could choose from a list of charities to which a $\$ 5$ donation would be made on their behalf. This study was approved by University of Central Florida's Institutional Review Board. Six participants failed manipulation checks (three in the Predictive-Nonfinancial condition, two in the Predictive-Financial condition, and one in the Anomaly-Financial condition). The results presented include these participants; however, excluding them from the analysis does not change the inferences drawn from this study except as noted in footnote 14. Despite passing both manipulation checks, one participant chose to decrease budgeted audit hours by 10 percent in response to the risk identified, and was excluded from the analysis.
} 
(78\%) were CPAs. Sixty-one participants (62\%) reported prior experience using data analytics. ${ }^{5}$

See Table 1 for additional demographic information.

[INSERT TABLE 1 HERE]

\section{Experimental Task and Procedure}

Using a case adapted from Brazel and Agoglia (2007), ${ }^{6}$ participants were told to assume the role of senior auditor for Madison Inc., a privately held midsize sporting equipment manufacturer. Participants received background information about the client and that their firm's Central Data Analytics Group identified possible unusual activity related to Madison's revenue cycle. ${ }^{7}$ While participants could have conducted analyses on their own, they were presented with conclusions from the Central Data Analytics Group as a way to affect cognitive fit without requiring them to spend significant time conducting analyses. The Central Data Analytics Group was described consistently across conditions.

To ensure that participants carefully considered the relevance of, and did not blindly rely on, information provided before incorporating it into their judgments, the client was described as low risk and the Central Data Analytics Group was described as not consisting of CPAs and at

\footnotetext{
${ }^{5}$ Sixty-eight percent of participants in both financial data conditions reported prior experience using data analytics. Sixty-two and a half and fifty percent of participants in the predictive-nonfinancial and anomaly-nonfinancial conditions, respectively, reported experience using data analytics. Prior experience using data analytics did not significantly differ across conditions $(p>0.10)$. However, it is important to note that the hypothesis is based on auditors' familiarity with the underlying analysis employed by data analytics, not necessarily the use of analytics. ${ }^{6}$ This case has been adapted by subsequent research (Hirsch 2020).

${ }^{7}$ Section 1.51 of the AICPA's Audit Data Analytics (ADA) guide provides documentation guidelines for auditors when using data analytics (as in the case of this study in which a central data analytics group provides the analysis). Per these guidelines, documentation may include the following:

- risks of material misstatement that the procedure intended to address at the financial statement level or at the assertion level

- The ADA and related tools and techniques used

- The identifying characteristics of the specific items or matters tested
} 
times making inaccurate judgments. ${ }^{8}$ Next, participants received an explanation of the underlying logic of the respective models and data analyzed. Participants were told that the Central Data Analytics Group identified a misstatement with a possible range just above performance materiality of $\$ 304,000$. Specifically, the conclusion reached read in part "Nonetheless, the Central Data Analytics Group stated that by using (predictive analytical models / anomaly analytical models) to analyze (journal entries / e-mails), they believe there is a $56 \%$ risk that revenue is overstated by some amount between $\$ 270,000$ and $\$ 310,000$." Participants were then asked about the extent they would change budgeted hours and rely on the unusual activity identified for their fraud risk assessment. After completing the case, participants answered manipulation check questions and completed demographic questions.

\section{Independent and Dependent Variables}

Two independent variables (the type of data analytical models used and type of data analyzed) were manipulated between participants resulting in a 2 X 2 design. The model type manipulation described the Central Data Analytics Group as using either anomaly or predictive models. To ensure participants understood the manipulation, I included a description of the models' application. In the anomaly models' condition, I informed participants that identification of unusual activity occurred by comparing Madison Inc.'s current year activity with the current year activity of other sporting goods manufacturing clients to identify high and low amounts. This is consistent with anomaly models' making high or low comparisons against a peer group (Cho et al. 2010; Li 2010; Humpherys et al. 2011; Price, Sharp, and Wood 2011; Davis and Tama-Sweet 2012; Hobson et al. 2012; SAS 2014; DHHS 2014). The manipulation discussing

\footnotetext{
${ }^{8}$ Informal conversations between the researcher and auditors from five international firms revealed that data scientist groups (or their equivalents) have provided documentation that contained errors or ambiguous information. One audit manager stated specifically, "In my experience, they are never spot on".
} 
the analysis by the anomaly models read, in part, "Anomaly models identify statistical outliers indicating very high or low amounts based on your firm's client base."

In the predictive model condition, I informed participants that identification of unusual activity occurred by identifying a similarity in Madison Inc.'s current year activity to the activity of a different sporting goods manufacturing client when that client had a material misstatement. This is consistent with predictive models' ability to identify future events using historical patterns (Dechow et al. 2011; Perols et al. 2017). The manipulation discussing the analysis by the predictive models read, in part, "Predictive models compare information in the data collected from clients associated with previously identified events/occurrences to current information."

I described the type of data analyzed as either financial or nonfinancial. For the financial data manipulation, the Central Data Analytics Group analyzed the ratio of the number of journal entries just below performance materiality to the total number of journal entries. ${ }^{9}$ For the nonfinancial data manipulation, the Central Data Analytics Group analyzed the ratio of optimistic language in external e-mails to that in internal e-mails..$^{10} \mathrm{E}$-mails have been analyzed as part of forensic audits, including by the Federal Trade Commission and the Department of Justice, and during the Enron investigation (Torpey, Walden, and Sherrod 2009, 2010; Debreceny and Gray 2011; Ernst and Young 2013; Beach and Schiefelbein 2014). Companies' use of optimistic language differs. For example, poorer environmental performers use more optimistic language in 10-K disclosures (Cho et al. 2010), and earnings press releases contain more optimistic language than MD\&A disclosures (Davis and Tama-Sweet 2012).

\footnotetext{
${ }^{9}$ This ratio is a risk factor. For example, the HealthSouth fraud began with numerous fraudulent journal entries just below performance materiality in an effort to avoid auditor detection (Beam 2015; Smith 2016).

${ }^{10} \mathrm{E}$-mails can provide an important source of evidence about the background and intent of managerial actions (Debreceny and Gray 2011), and have been used by the SEC to monitor credit agencies (SEC 2008).
} 
Participants responded to how they would change budgeted audit hours for revenue from the initial budget of 30 hours as the primary dependent variable. A sliding scale anchored at negative 100 percent and positive 100 percent measured the primary dependent variable (Bud). The reliance scale from Hampton (2005) was adapted and the total scale was included as a second dependent variable ( $R e l$ ) to measure participants' likelihood of relying on the conclusions from the analytics for their fraud risk assessment. ${ }^{11}$ Because the instrument described the risk identified as "unusual activity" and not a fraud risk, budgeted audit hours was chosen as the dependent variable (as opposed to reliance for fraud risk).

The five items comprising the Rel variable were measured on seven-point Likert scales. The first item elicited participants' belief that the information identified by the data analytics represents a fraud risk. The second item measured participants' confidence in the accuracy of the information identified by the data analytics. The third item measured the participants' level of confidence in evaluating fraud risk without the data analytics and was reverse coded. Item four addressed participants' willingness to incorporate the findings from the data analytics into their fraud risk assessment. The final item captured participants' willingness to rely on the findings from the data analytics. To assess the reliability of Rel, Cronbach's alpha was calculated as 0.83 , which is above the recommended threshold of 0.70 (Nunnally 1978).

\section{RESULTS - EXPERIMENT}

\section{Identification of Potential Covariates}

Participants in all conditions provided information regarding their experience using data analytics, specifically with both anomaly and predictive models. Participants with experience

\footnotetext{
${ }^{11}$ Participants' Fraud Risk Assessment was also measured, but did not differ across conditions. While cognitive fit has been shown to affect task completion time (Dunn et al. 2017), completion time was not examined because some participants appeared to complete the task over more than one sitting.
} 
using data analytics were asked to respond on two five-point Likert scales regarding how experienced they were at using anomaly and predictive models with endpoints of "Not at all experienced" (1) and "Extremely experienced" (5). A t-test revealed no significant difference $(\mathrm{t}=$ 0.497) in participants' experience using predictive models (mean 2.559) as compared with anomaly models (mean 2.590). ${ }^{12}$ This demonstrates the use of anomaly models at comparable levels to predictive models in practice. Examination of demographic variables for potential covariates identified the participants' employer size as a covariate for Bud such that, participants employed by larger firms recommended greater budgeted audit hours.

\section{Test of Hypotheses}

Table 2 Panel A provides descriptive statistics for the Bud dependent variable. The descriptive statistics show that on average, participants across conditions increased budgeted audit hours by approximately 16 percent. The ANCOVA results presented in Table 2 Panel B show that conclusions from the type of data analytical model used interacts with the type of data analyzed to affect participants' determination of budgeted audit hours $(F=6.20, p=0.015)$. The results presented in Table 2 support the Hypothesis. ${ }^{13}$ These results demonstrate that when data analytics analyze nonfinancial data, participants increase budgeted audit hours more in response to conclusions from anomaly models than to those from predictive models. The opposite is true for data analytics analyzing financial data: participants increase budgeted audit hours more in

\footnotetext{
${ }^{12}$ All statistical tests presented are two tailed. The means are less than the midpoint of the scale labeled "Moderately experienced" ( $p<0.01$ in both instances). Participants with data analytics experience reported more experience using anomaly models in the predictive conditions than in the anomaly conditions ( $2.97 \mathrm{vs.} 2.17, \mathrm{p}<0.01)$. Yet prior experience using anomaly models was not a significant covariate $(\mathrm{p}=0.47)$ when included in the primary ANCOVA. ${ }^{13}$ Additional analysis was conducted (1) excluding directors and partners, (2) excluding staff, (3) excluding auditors employed by local firms (with and without the size covariate), (4) replacing the Size variable with an indicator variable for being employed by an international firm, (5) including an indicator variable for managers, directors, and partners, (6) including an indicator variable for staff, (7) excluding the Size covariate, (8) controlling for professional experience, (9) controlling for Audit Experience, and (10) controlling for Age. The Hypothesis remained supported in all instances.
} 
response to conclusions from predictive models than to those from anomaly models. Thus, firms can enhance audit effort in response to identified audit risks by tailoring the type of data analyzed by different analytical models. Figure 1 provides a graphical representation of the results for the Bud dependent variable.

[INSERT TABLE 2 HERE]

\section{[INSERT FIGURE 1 HERE]}

Because of the significant interactive effect $(p=0.015)$ on budgeted audit hours identified in Table 2 Panel B, I analyzed simple effects while controlling for employer firm size. Results are presented in Table 2 Panel C. Although simple effects are not appropriate as the sole test of an interaction, they can provide a supplemental test of theory (Guggenmos et al. 2018). The results presented in Table 2 Panel $C$ show that the effect of the type of data analytical models used on budgeted audit hours depends on the type of data analyzed. Specifically, when a conclusion was reached from analyzing financial data, participants increase budgeted audit hours more in response to unusual activity identified by predictive models as compared with anomaly models $(\mathrm{F}=2.88, \mathrm{p}=0.093) \cdot{ }^{14}$ Alternatively, when a conclusion was reached from analyzing nonfinancial data, participants increase budgeted audit hours more in response to unusual activity identified by anomaly models as compared with predictive models $(F=3.33, \mathrm{p}=0.071)$. These results provide additional support for the Hypothesis.

Additional analysis examined participants' increase in budgeted audit hours when predictive analytics analyzed different types of data. Results indicate that when predictive models were used to draw conclusions, participants increase budgeted audit hours more when these models analyzed financial data than when the analyzed nonfinancial data $(F=6.86, p=$

\footnotetext{
${ }^{14}$ Excluding participants that failed manipulation checks results in this finding becoming insignificant $(\mathrm{p}>0.10)$.
} 
0.010). However, participants' increase in budgeted audit hours did not differ based on the type of data analyzed by anomaly models $(\mathrm{F}=0.82, \mathrm{p}=0.366) .{ }^{15}$

Table 3 Panel A provides descriptive statistics for the Rel dependent variable to measure auditors' reliance on the conclusions from the analytics for their fraud risk assessment. The descriptive statistics show that, on average, participants across conditions were slightly willing to rely on the conclusions from the analytics for their fraud risk assessment. The ANCOVA results presented in Table 3 Panel B show that conclusions from the type of data analytical model and the type of data analyzed do not jointly influence auditors' reliance on the analytics for their fraud risk assessments $(\mathrm{F}=0.32, \mathrm{p}=0.571)$. The lack of support for the Rel variable in light of support for the Bud variable may be attributable to auditors' higher threshold to raise fraud risk given the substantial amount of follow-up work required when increasing fraud risk as opposed to budgeted audit hours.

\section{METHOD - INTERVIEWS}

Consistent with the experiment above, prior accounting research examining cognitive fit tends not to include a measured cognitive fit variable. For example, prior accounting cognitive fit research manipulates information presentation formats (Dunn and Grabski 2001; Dunn et al. 2017; Dunn and Grabski 2000; Frownfelter-Lohrke 1998; Dilla and Steinbart 2005), and

\footnotetext{
${ }^{15}$ I considered the possibility that the predictive-nonfinancial condition was driving the results by having the lowest mean, but represents a scenario that does not occur in practice. If this condition never exists in practice, participants decisions may have been attributable to a lack ability to make an informed decision in this scenario, rather than a lack of cognitive fit. I took two measures to ensure that an unrealistic condition was not driving the results: First, examination of interview data (see below) revealed that predictive analytics indeed analyze non-financial data (although much less common than analyzing financial data). Therefore, auditors have experience, albeit limited, using predictive analytics to analyze financial data and the predictive-nonfinancial condition is not a scenario that never occurs in practice. Second, following the guidance set forth by Guggenmos et al. (2018), results of a planned contrast, while controlling for employer firm size, revealed that participants in the predictive-nonfinancial condition recommended the lowest increase in budgeted hours $(\mathrm{F}=4.83, \mathrm{p}=0.031)$ and that participants in the predictivefinancial condition recommended the greatest increase in budgeted hours $(F=4.30, p=0.041)$. These results are consistent with the graphical depiction of results in Figure 1 and the simple effects shown in Table 2 Panel C. Taken together, the results of the planned contrasts show that support for the hypothesis is not driven by only one of the financial data conditions.
} 
participants level of education (i.e., undergraduate student vs. graduate student) (Dunn and Grabski 2001; Noga and Arnold 2002). Although measuring cognitive fit in the initial experiment with all participants using a well established and validated scale would have been the optimal approach, unfortunately a limitation of prior research is that no such scale exists.

Given the lack of a well established and generally accepted scale to measure cognitive fit, I was unable to reliably measure cognitive fit in the experiment. To address this limitation, I conducted follow up interviews with 26 participants who self-reported completing the experiment. This allowed me to explore the relationship between auditors' prior experience and familiarity with different analyses, and the results of the experiment. Conducting these interviews allowed me to collect first hand experience-related data (e.g., participants experience using data analytics as well as how this experience increases cognitive fit and the likelihood of adoption of the analytics) from part of the initial sample and examine cognitive fit at the time of the initial experiment (Malsch and Salterio 2016). ${ }^{16}$ Ultimately, conducting interviews allowed me to understand the complexity of auditors behavior beyond capturing a single (unvalidated) cognitive fit measure.

Semi-structured interviews were used to collect data on topics of interest, while permitting the researcher to be flexible during the interview (Miller and Crabtree 1994). The results from the experiment demonstrate that auditors use predictive and anomaly models at comparable levels, thus I did not ask interviewees to compare their use of predictive and anomaly analytics (a required criteria for being interviewed was self-reporting completing the experiment, so I already captured this data from interviewees). Rather, the focus of the interviews was on factoring impacting data analytic adoption and use (i.e., cognitive fit) and the

\footnotetext{
${ }^{16}$ While I considered conducting an additional experiment, this approach would require development and validation
} of a cognitive fit scale, likely following a process similar to Hurtt (2010), and is beyond the scope of this study. 
proportion of time the interviewees had experience with the individual models analyzing different data. Interviewees were asked about their experience using predictive and anomaly analytics to prompt recall of their experience using these analytics. Next, I asked interviewees to compare their level of experience using each analytical model analyzing financial and nonfinancial data. Finally, I asked interviewees about factoring impacting data analytic use. See Appendix A for the interview protocol. ${ }^{17}$ The interviews lasted an average of 24 minutes and were conducted via Zoom or phone. All but one interview was recorded and subsequently fully transcribed by the researcher or a research assistant.

A data-centric analysis was employed (Benbasat et al. 1987; Eisenhardt 1989; Miles and Huberman 1994; Yin 2009), which views data as "an entity representing a fixed meaning, and emphasizes the use of systematic logical operations of the data to derive knowledge or findings" (Sarker et al. 2018a, 761). I coded the data by identifying quotes discussing familiarity with processes used by analytics and experience using analytics as factors impacting use of analytics and making comparisons between different data analytic inputs. These quotes were compiled to accomplish data display and aid in the conclusion drawing/verification process (O’Dwyer 2004; O’Dwyer 2011; O'Dwyer et al. 2011), with the quotes best supporting the main findings being selected for inclusion below. Given the need for objectivity of coding and analysis in qualitative studies (Malsch and Salterio 2016; Power and Gendron 2015; Sarker et al. 2018b), to ensure the accuracy, reliability, validity, and trustworthiness of the findings, a research assistant independently followed the same process. ${ }^{18}$ Data saturation, the point at which additional

\footnotetext{
${ }^{17}$ The interview protocol was modified after the second interview.

${ }^{18}$ Cohen's Kappa was 0.814 , which is above the recommended threshold of 0.80 (Neuendorf 2002). All coding discrepancies were resolved.
} 
interviews did not contradict nor add any significant information (Sutton et al. 2011; Malsch and Salterio 2016), was achieved.

\section{RESULTS - INTERVIEWS}

Consistent with prior cognitive fit literature, interviewees discussed that an understanding of the processes used by the analytics (Vessey and Galletta 1991; Arnold and Sutton 1998; AlNatour et al. 2008), and prior experience using the analytics (Goodhue and Thompson 1995; Dunn and Grabski 2001), increases their likelihood to use conclusions from the analytics. Interviewee's also discussed their experience using analytics with different inputs in line with the argument set forth in the literature review. Taken together, the interviews provide evidence for experience using familiar analyses increasing adoption of data analytics, and the results of the experiment being attributable to cognitive fit.

Interviewees discussed the need to understand and experience cognitive fit with the analysis performed by the analytics to use the conclusions from the analytics. This need to understand, attributable to a lack of cognitive fit, is in line with decision makers need to mentally transform unfamiliar information into a useful format (Nisbett and Ross 1980). Specifically, interviewees noted:

[when using new method or data being] ... a little potentially aware that I have never looked at this before or done it before. ... I would want to make sure that I had the right thought process or have the right data and want to make sure everything is right before I jump to any conclusions (Interviewee \#7)

I think if someone can understand how the analytics are getting to their certain conclusion then I think that that's really helpful (Interviewee \#18)

Interviewees also discussed how prior experience using analytics induces use of the analytics. This is in line with prior literature highlighting prior experience induces cognitive fit 
(Goodhue and Thompson 1995; Dunn and Grabski 2001), and use of information. Interviewees specifically stated:

I think, you know, it all comes down to your experience using it ... So I'd say those are probably the largest one [resistance to using analytics] is the lack of experience ... and I think that's why people would push away from using data analytics (Interviewee \#24) anytime there's new data, I'm a little bit nervous. ... has it been done before? Is it tried and true? If it's tried and true or if it's been used and it's worked ... I think if it's been tried before, an auditor's willingness [to use the analytics] will increase. If the auditor has experience with the process or with the client I think there can probably be higher willingness to use certain analytics. (Interviewee \#16)

\section{Experience with different inputs}

The results from the experiment demonstrate that auditors have comparable experience using anomaly and predictive models. Consistent with the argument in the literature review, overall, interviewees highlighted the tendency for predictive analytics to focus on the analysis of financial data, as opposed to nonfinancial data. Alternatively, the use of anomaly analytics tended to focus more on a mix of financial and nonfinancial data. While interviewees discussed a greater focus of predictive analytics on financial data than anomaly analytics, they acknowledged that these analytics analyze nonfinancial data. Interviewees discussed the tendency for predictive analytics to focus on analysis of financial data when stating:

80 percent are a number $\ldots$ based on financial data and then the other 20 percent is ... nonfinancial. (Interviewee \#4)

Primarily financial data was the focus. In order to interpret the results, we certainly needed to have nonfinancial data, but all of the inputs were financial. (Interviewee \#17)

My experience personally with nonfinancial data is probably limited. So, I think in terms of financial data ... it's more prevalent. (Interviewee \#18)

In discussions of the use of anomaly analytics, such a distinction between analysis of financial and nonfinancial data was not as apparent. Interviewees discussed greater use of 
nonfinancial data for anomaly analytics than for predictive analytics. Interviewees discussed the use of nonfinancial data being a necessary piece of analysis performed by anomaly analytics:

It's kind of hard to detach the two [financial and nonfinancial data] from each other. It's because you kind of use your knowledge of any nonfinancial circumstances to kind of frame what would be your anomalies. (Interviewee \#6)

For the anomaly analytics, I don't think that there was a disparity within inputs (Interviewee \#13)

... we did compare that financial data to nonfinancial data ... we did put a lot of weight I think into the nonfinancial [data]. (Interviewee \#16)

\section{CONCLUSION}

Technological advancements have enabled the development of more sophisticated data analytics. These analytics hold the potential to improve the audit process by facilitating analysis of larger data sets of traditional data (Jans et al. 2014), along with analysis of new types of data (Warren et al. 2015; PCAOB 2016; Agnew 2016a; IAASB 2017). Despite the interest from practice to increase the use of data analytics throughout the audit process (IAASB 2017; PCAOB 2016; PCAOB 2018b), limited empirical research has examined the impact of data analytics on auditors' decisions, including a lack of research examining analytic inputs (Rose et al. 2017).

This study contributes to the literature by providing initial empirical evidence that conclusions from different data analytic inputs influence auditors' decisions. When auditors view conclusions from data analytics that analyzed financial data, they increase budgeted hours more from predictive models than from anomaly models. The opposite is true when they view conclusions from analysis of nonfinancial data: a greater increase in budgeted hours occurs from anomaly models than from predictive models. The results of this study suggest that using data analytics to increase audit quality will require more than presenting auditors with the conclusions from the data analytics. Specifically, auditors' reliance on the analytics varies according to 
factors such as cognitive fit, and may vary according to the other variables TTD discusses. However, firms can capitalize on these differences to enhance auditor effort by simply tailoring the type of data analyzed with different data analytical models.

The results of this study contribute to the TTD and cognitive fit literature by demonstrating that cognitive fit with data analytics influences budgeted audit hours decisions. In line with TTD, I find that greater cognitive fit is influenced by users' prior training and experience (Goodhue and Thompson 1995; Dunn and Grabski 2001), and these differences in experience contribute to different levels of cognitive fit and ultimately decision-making. Followup interviews with participants from the experiment showed that participants had greater experience using predictive analytics that analyze financial data as compared with nonfinancial data, yet this difference is not as apparent for anomaly analytics. These experience levels analyzing different analyses are consistent with auditors' change in budgeted hours.

Because this is the first study to empirically examine auditors' use of data analytics with different inputs, it has some limitations, along with opportunities for future research. A limitation of this study is that it examined only two types of data analytical models that analyzed two types of data on one outcome. Future research could examine how the inputs in this study and other inputs (for example, analysis of internal versus external data) resulting in different outputs (such as visualizations versus text) influence auditors' decisions when using data analytics. Future research should seek to examine what combination of data analytical models (i.e., using anomaly models in conjunction with rules-based models ${ }^{19}$ ) and data results in the greatest change in auditors' decisions, because using multiple data types provides more useful insights than relying

\footnotetext{
${ }^{19}$ Rules based analytics identify data based on predetermined criteria (SAS 2014) and can identify when violations of established business processes exceed a predetermined threshold (Jans, Lybaert, and Vanhoof 2010; Jans, Alles, and Vasarhelyi 2013), and when transactions exceed a certain threshold (Christensen, Glover, and Wood 2012).
} 
on only one type of data (Richins et al. 2017). Given that internal auditors' decisions affect senior management (Carcello, Eulerich, Masli, and Wood 2018; Carcello, Eulerich, Masli, and Wood 2020), and operating performance (Jiang, Messier, and Wood 2020), future research may seek to examine the impact that data analytics have on internal auditors' judgments. Further, extant research provides mixed results about auditors' performance using decision-aiding tools (Beck, Limor, Arunchalam, and Wheeler 2014). Therefore, future research may seek to examine how auditors' use of data analytics with inherent biases affects performance and what remediation strategies (Farkas and Hirsch 2016) may be effective at reducing these biases.

Another limitation of this study is that cognitive fit was not directly measured in the initial experiment. Unfortunately, a limitation of several cognitive fit studies in accounting is not measuring cognitive fit (Dunn and Grabski 2001; Dunn et al. 2017; Dunn and Grabski 2000; Frownfelter-Lohrke 1998; Dilla and Steinbart 2005), which is likely somewhat attributable to a lack of a generally accepted scale to measure cognitive fit. While I was able to obtain data related cognitive fit from some of the participants in the initial experiment to partially mitigate this limitation, future research should develop and validate a scale to measure cognitive fit (potentially following a process similar to Hurtt (2010)) to better test cognitive fit theory.

These results highlight the importance of public accounting firms to properly train their employees on the use of data analytics to enhance cognitive fit and facilitate uniform decisionmaking. Thus, future research could examine how to most effectively induce auditors' use of data analytics to improve decision making. For example, despite individuals' aversion to trainings (Baxter, Holderness, and Wood 2016), future research may seek to examine the most effective training methods to induce auditors' reliance on data analytics. Finally, because 
auditors have been shown to underreport hours, future research may seek to examine auditors' likelihood of underreporting hours using data analytics (Pickerd, Summers, and Wood 2015). 


\section{REFERENCES}

Agarwal, R., A. P. Sinha, and M. Tanniru. 1996. Cognitive fit in requirements modeling: A study of object and process methodologies. Journal of Management Information Systems 13 (2): $137-162$.

Agnew, H. 2016a. PwC seeks more data scientists to analyse deals. Financial Times February 1. - 2016b. Auditing: Pitch battle. Financial Times May 9.

Al-Natour, S., I. Benbasat, and R. T. Cenfetelli. 2008. The effects of process and outcome similarity on users' evaluations of decision aids. Decision Sciences 39 (2): 175-211.

Alles, M., and G. L. Gray. 2015. The pros and cons of using big data in auditing: A synthesis of the literature and a research agenda. Working paper.

Ameen, E. C., and J. R. Strawser. 1994. Investigating the use of analytical procedures: an update and extension. Auditing: A Journal of Practice \& Theory 13 (2): 69-76.

American Institute of Certified Public Accountants (AICPA). 2015a. Audit analytics and continuous audit: Looking toward the future. New York, NY.

-2015b. Audit data standards - Base standard.

2017. Guide to audit data analytics.

Amir, E., and B. Lev. 1996. Value-relevance of nonfinancial information: The wireless communications industry. Journal of Accounting and Economics 22 (1-3): 3-30.

Appelbaum, D., A. Kogan, and M. A. Vasarhelyi. 2017. Big data and analytics in the modern audit engagement: Research needs. Auditing: A Journal of Practice \& Theory 36 (4): 1-27.

Arnold, V., and S. G. Sutton. 1998. The theory of Technology Dominance: Understanding the impact of Intelligent Decision Aids on decision makers' judgments. Advances in Accounting Behavioral Research 1: 175-194.

Asare, S. K., A. M. Wright, and G. M. Trompeter. 2000. The effect of accountability and time budgets on auditors' testing strategies. Contemporary Accounting Research 17 (4): 539560 .

Austin, A., T. D. Carpenter, M. H. Christ, and C. Nielson. 2019. The data analytics transformation: Evidence from auditors, CFOs, and standard setters. Working paper.

Ballou, B., J. H. Grenier, and A. B. Reffett. 2019. Stakeholder perceptions of data and analytics based auditing techniques. Working paper.

Barr-Pulliam, D., J. F. Brazel, J. McCallen, and K. Walker. 2020. Data analytics and skeptical actions: The countervailing effects of false positives and consistent rewards for skepticism. Working paper.

Baxter, R. J., D. K. Holderness, and D. A. Wood. 2016. Applying basic gamification techniques to IT compliance training: Evidence from the lab and field. Journal of Information Systems 30 (3): 119-133.

Beach, C. S., and J. D. Schiefelbein. 2014. Unstructured data: How to implement an early warning system for hidden risks. Journal of Accountancy 217 (1): 1-5. 
Beam, A. 2015. Fraud, lies \& hermes ties. Las Vegas, NV: AICPA Health Care Industry Conference.

Beck, G. M., R. Limor, V. Arunachalam, and P. R. Wheeler. 2014. The effect of changes in decision aid bias on learning: Evidence of functional fixation. Journal of Information Systems 28 (1): 19-42.

Benbasat, I., D. K. Goldstein, and M. Mead. 1987. The case research strategy in studies of information systems. MIS Quarterly 11 (3): 369-386.

Brazel, J. F., and C. P. Agoglia. 2007. An examination of auditor planning judgements in a complex accounting information system environment. Contemporary Accounting Research 24 (4): 1059-1083.

Brazel, J. F., K. L. Jones, and D. F. Prawitt. 2014. Auditors' reactions to inconsistencies between financial and nonfinancial measures: The interactive effects of fraud risk assessment and a decision prompt. Behavioral Research in Accounting 26 (1): 131-156.

Brazel, J. F., K. L. Jones, and M. F. Zimbelman. 2009. Using nonfinancial measures to assess fraud risk. Journal of Accounting Research 47 (5): 1135-1166.

Brazel, J. F., and J. Schmidt. 2019. Do auditors and audit committees lower fraud risk by constraining inconsistencies between financial and nonfinancial measures? Auditing: A Journal of Practice \& Theory 38 (1): 103-122.

Brewster, B. E. 2011. How a systems perspective improves knowledge acquisition and performance in analytical procedures. The Accounting Review 86 (3): 915-943.

Brown-Liburd, H., H. Issa, and D. Lombardi. 2015. Behavioral implications of big data's impact on audit judgment and decision making and future research directions. Accounting Horizons 29 (2): 451-468.

Carcello, J. V., M. Eulerich, A. Masli, and D. A. Wood. 2018. The value to management of using the internal audit function as a management training ground. Accounting Horizons 32 (2): $121-140$.

-2020. Are internal audits associated with reductions in perceived risk. Auditing: A Journal of Practice \& Theory 39 (3): 55-73.

Cho, C. H., R. W. Roberts, and D. M. Patten. 2010. The language of US corporate environmental disclosure. Accounting, Organizations and Society 35 (4): 431-443.

Christensen, B. E., S. M. Glover, and D. A. Wood. 2012. Extreme estimation uncertainty in fair falue estimates: Implications for audit assurance. Auditing: A Journal of Practice \& Theory 31 (1): $127-146$.

Coffey, S. 2015. Rutgers and AICPA unveil data analytics research initiative. Business Wire. http://www.businesswire.com/news/home/20151216005745/en/Rutgers-AICPA-UnveilData-Analytics-Research-Initiative\#.VnK69OJGTvA.email.

Cohen, J. R., G. Krishnamoorthy, and A. M. Wright. 2000. Evidence on the effect of financial and nonfinancial trends on analytical review. Auditing: A Journal of Practice \& Theory 19 (1): 27-48.

Cooper, L. A., D. K. Holderness, T. Sorensen, and D. A. Wood. 2019. Robotic process 
automation in public accounting. Accounting Horizons 33 (4): 15-35.

. 2021. Perceptions of Robotic Process Automation in Big 4 public accounting firms: Do firm leaders and lower-level employees agree? Journal of Emerging Technologies in Accounting (Forthcoming).

Davis, A. K., and I. Tama-Sweet. 2012. Managers' use of language across alternative disclosure outlets: Earnings press releases versus MD\&A. Contemporary Accounting Research 29 (3): 804-837.

Davis, F., R. P. Bagozzi, and P. R. Washaw. 1989. User acceptance of computer technology: A comparison of two theoretical models. Management Science 35 (8): 982-1003.

Debreceny, R. S., and G. L. Gray. 2011. Data mining of electronic mail and auditing: A research agenda. Journal of Information Systems 25 (2): 195-226.

Dechow, P. M., W. Ge, C. R. Larson, and R. G. Sloan. 2011. Predicting material accounting misstatements. Contemporary Accounting Research 28 (1): 17-82.

Deloitte. 2013. Adding insight to audit transforming internal audit through data analytics.

- 2018a. Solve for now. Build for next. The Deloitte audit.

- 2018b. Life at Deloitte: Data science careers at Deloitte.

Department of Health and Human Services. 2014. Report to Congress: Fraud prevention system second implementation year.

- 2015. Report to Congress: Fraud prevention system third implementation year.

Diaz, M. C., and T. M. Loraas. 2010. Learning new uses of technology while on an audit engagement: Contextualizing general models to advance pragmatic understanding. International Journal of Accounting Information Systems 11 (1): 61-77.

Dilla, W. N., and P. J. Steinbart. 2005. Using information display characteristics to provide decision guidance in a choice task under conditions of strict uncertainty. Journal of Information Systems 19 (2): 29-55.

Dunn, C., G. J. Gerard, and S. V. Grabski. 2017. The combined effects of user schemas and degree of cognitive fit on data retrieval performance. International Journal of Accounting Information Systems 26: 46-67.

Dunn, C., and S. V. Grabski. 2000. Perceived semantic expressiveness of accounting systems and task accuracy effects. International Journal of Accounting Information Systems 1 (2): 79-87.

-2001. An investigation of localization as an element of cognitive fit in accounting model representations. Decision Sciences 32 (1): 55-94.

Eisenhardt, K. M. 1989. Building theories from case study research. Academy of Management Review 14 (4): 532-550.

Emett, S. A., S. E. Kaplan, E. G. Mauldin, and J. S. Pickerd. 2019. Auditing with data and analytics: External reviewer perceptions of audit quality. Working paper.

Ernst and Young. 2013. Forensic data analytics.

-2015. Analytics: Don’t forget the human element. 
Eulerich, M., and A. Kalinichenko. 2018. The current state and future directions of continuous auditing research: An analysis of the existing literature. Journal of Information Systems 32 (3): $31-51$.

Farkas, M. J., and R. M. Hirsch. 2016. The effect of frequency and automation of internal control testing on external auditor reliance on the internal audit function. Journal of Information Systems 30 (1): 21-40.

Frownfelter-Lohrke, C. 1998. The effects of differing information presentations of general purpose financial statements on users' decisions. Journal of Information Systems 12 (2): 99-107.

Glover, S. M., D. F. Prawitt, and T. J. Wilks. 2005. Why do auditors over-rely on weak analytical procedures? The role of outcome and precision. Auditing: A Journal of Practice \& Theory 24 (Supplement): 197-220.

Goodhue, D. L., and R. L. Thompson. 1995. Task-technology fit and individual performance. MIS Quarterly 19 (2): 213-236.

Grover, V., R. H. L. Chiang, T.-P. Liang, and D. Zhang. 2018. Creating strategic business value from big data analytics: A research framework. Journal of Management Information Systems 35 (2): 388-423.

Guggenmos, R. D., M. D. Piercey, and C. P. Agoglia. 2018. Custom contrast testing: Current trends and a new approach. The Accounting Review 93 (5): 223-244.

Hampton, C. 2005. Determinants of reliance: An empirical test of the theory of technology dominance. International Journal of Accounting Information Systems 6 (4): 217-240.

Hirsch, R. M. 2015. Knowledge resources and book reviews. Journal of Information Systems 29 (1): 163-166.

-2020. The effect of spatial distance and domain knowledge distinctiveness on auditor reliance on IT specialists. Journal of Information Systems 34 (1): 81-103.

Hirst, D. E., and L. Koonce. 1996. Audit analytical procedures: A field investigation. Contemporary Accounting Research 13 (2): 457-486.

Hobson, J. L., W. J. Mayew, and M. Venkatachalam. 2012. Analyzing speech to detect financial misreporting. Journal of Accounting Research 50 (2): 349-392.

Holton, C. 2009. Identifying disgruntled employee systems fraud risk through text mining: A simple solution for a multi-billion dollar problem. Decision Support Systems 46 (4): 853864.

Huerta, E., and S. Jensen. 2017. An accounting information systems perspective on data analytics and big data. Journal of Information Systems 31 (3): 101-114.

Humpherys, S. L., K. C. Moffitt, M. B. Burns, J. K. Burgoon, and W. F. Felix. 2011. Identification of fraudulent financial statements using linguistic credibility analysis. Decision Support Systems 50 (3): 585-594.

Hurtt, R. K. 2010. Development of a scale to measure professional skepticism. Auditing: A Journal of Practice \& Theory 29 (1): 149-171.

International Auditing and Assurance Standards Board. 2017. Data analytics. IAASB Projects. 
http://www.iaasb.org/projects/data-analytics.

Issa, H., and A. Kogan. 2014. A predictive ordered logistic regression model as a tool for quality review of control risk assessments. Journal of Information Systems 28 (2): 209-229.

Jans, M., M. G. Alles, and M. A. Vasarhelyi. 2014. A field study on the use of process mining of event logs as an analytical procedure in auditing. The Accounting Review 89 (5): 17511773.

Jans, M., M. Alles, and M. A. Vasarhelyi. 2013. The case for process mining in auditing: Sources of value added and areas of application. International Journal of Accounting Information Systems 14 (1): 1-20.

Jans, M., N. Lybaert, and K. Vanhoof. 2010. Internal fraud risk reduction: Results of a data mining case study. International Journal of Accounting Information Systems 11 (1): 17-41.

Jiang, L., W. F. Messier, and D. A. Wood. 2020. The association between internal audit operations-related services and firm operating performance. Auditing: A Journal of Practice \& Theory 39 (1): 101-124.

Kelton, A. S., R. R. Pennington, and B. M. Tuttle. 2010. The effects of information presentation format on judgment and decision making: A review of the information systems research. Journal of Information Systems 24 (2): 79-105.

Knapp, C. A., and M. C. Knapp. 2001. The effects of experience and explicit fraud risk assessment in detecting fraud with analytical procedures. Accounting, Organizations and Society 26 (1): 25-37.

Kogan, A., M. G. Alles, M. A. Vasarhelyi, and J. Wu. 2014. Design and evaluation of a continuous data level auditing system. Auditing: A Journal of Practice \& Theory 33 (4): 221-245.

Koreff, J., and S. Perreault. 2020. Is sophistication always better? The impact of supervisor preferences and perceived data analytic tool sophistication on the evaluation of complex estimates. Working paper.

KPMG. 2012. Leveraging data analytics and continuous auditing processes for improved audit planning, effectiveness, and efficiency.

Krahel, J. P., and W. R. Titera. 2015. Consequences of big data and formalization of accounting and auditing standards. Accounting Horizons 29 (2): 409-422.

Kuenkaikaew, S., and M. A. Vasarhelyi. 2013. The predictive audit framework. The International Journal of Digital Accounting Research 13: 37-71.

Li, F. 2010. The information content of forward-looking statements in corporate filings-A naive bayesian machine learning approach. Journal of Accounting Research 48 (5): 1049-1102.

Loraas, T. M., and M. C. Diaz. 2011. Learning new technologies: The effect of ease of learning. Journal of Information Systems 25 (2): 171-194.

Loraas, T. M., and C. J. Wolfe. 2006. Why wait? Modeling factors that influence the decision of when to learn a new use of technology. Journal of Information Systems 20 (2): 1-23.

Loughran, T., and B. Mcdonald. 2016. Textual analysis in accounting and finance: A survey. Journal of Accounting Research 54 (4): 1187-1230. 
Luippold, B. L., and T. E. Kida. 2012. The impact of initial information ambiguity on the accuracy of analytical review judgments. Auditing: A Journal of Practice \& Theory 31 (2): $113-129$.

Malsch, B., and S. E. Salterio. 2016. "Doing good field research": Assessing the quality of audit field research. Auditing: A Journal of Practice \& Theory 35 (1): 1-22.

Masselli, J. J., R. C. Ricketts, V. Arnold, and S. G. Sutton. 2002. The impact of embedded intelligent agents on tax-reporting decisions. Journal of the American Taxation Association 24 (2): $60-78$.

Messier, W. F. 1995. Research in and development of audit decision aids. In Judgment and Decision-Making Research in Accounting and Auditing, edited by R. H. Ashton and A. H. Ashton, 207-227. Cambridge: Cambridge University Press.

Messier, W. F., C. A. Simon, and J. L. Smith. 2013. Two decades of behavioral research on analytical procedures: What have we learned? Auditing: A Journal of Practice \& Theory 32 (1): 139-181.

Miles, M. B., and A. M. Huberman. 1994. Qualitative data analysis: An expanded sourcebook. Thousand Oaks, California: Sage Publications.

Miller, W., and B. Crabtree. 1994. Clinical research. In Handbook of qualitative research, 340252. Thousand Oaks, California: Sage Publications.

Nallareddy, S., and M. Ogneva. 2017. Predicting restatements in macroeconomic indicators using accounting information. The Accounting Review 92 (2): 151-182.

Neuendorf, K. A. 2002. The content analysis guidebook. Thousand Oaks, California: Sage Publications.

Nisbett, R., and L. Ross. 1980. Human inferences: Strategies and shortcomings of social judgment. Englewood Cliffs, NJ: Prentice Hall.

Noga, T., and V. Arnold. 2002. Do tax decision support systems affect the accuracy of tax compliance decisions? International Journal of Accounting Information Systems 3 (3): 125144.

Nunnally, J. 1978. Psychometric theory. 2nd ed. McGraw-Hill.

O’Donnell, E. F., and J. J. Schultz. 2003. The influence of business-process-focused audit support software on analytical procedures judgments. Auditing: A Journal of Practice \& Theory 22 (2): 265-279.

- 2005. The halo effect in business risk audits: Can strategic risk assessment bias auditor judgment about accounting details? The Accounting Review 80 (3): 921-939.

O’Dwyer, B. 2004. Qualitative data analysis: Exposing a process for transforming a "messy" but "attractive" "nusance". In A real life guide to accounting research: A behind the scenes view of using qualitative research methods. Amsterdam: Elsevier.

- 2011. The case of sustainability assurance: Constructing a new assurance service. Contemporary Accounting Research 28 (4): 1230-1266.

O’Dwyer, B., D. Owen, and J. Unerman. 2011. Seeking legitimacy for new assurance forms: The case of assurance on sustainability reporting. Accounting, Organizations and Society 36 (1): 
$31-52$.

Perols, J., R. M. Bowen, C. Zimmermann, and B. Samba. 2017. Finding needles in a haystack: Using data analytics to improve fraud prediction. The Accounting Review 92 (2): 221-245.

Pickerd, J. S., S. L. Summers, and D. A. Wood. 2015. An examination of how entry-level staff auditors respond to tone at the top vis-à-vis tone at the bottom. Behavioral Research in Accounting 27 (1): 79-98.

Power, M., and Y. Gendron. 2015. Qualitative research in auditing: A methodological roadmap. Auditing: A Journal of Practice \& Theory 34 (2): 147-165.

Price, R. A., N. Y. Sharp, and D. A. Wood. 2011. Detecting and predicting accounting irregularities: A comparison of commercial and academic risk measures. Accounting Horizons 25 (4): 755-780.

PriceWaterhouseCoopers. 2015. Data Driven: What students need to succeed in a rapidly changing business world.

Public Company Accounting Oversight Board. 2007a. Observations on auditors' implementation of PCAOB standards relating to auditors responsibilities with respect to fraud. Washington, $\mathrm{DC}$.

- 2007b. Report on the PCAOB's 2004, 2005, and 2006 inspections of domestic triennially inspected firms. Washington, DC.

- 2008. Report on the PCAOB's 2004, 2005, 2006, and 2007 inspections of domestic annually inspected firms. Washington, DC.

- 2013. Report on 2007-2010 inspections of domestic firms that audit 100 or fewer public companies. Washington, DC.

-2014. Staff audit practice alert no. 12. Washington, DC.

- 2016. Current priorities of the PCAOB. NYSSCPA SEC Conference.

- 2018a. Strategic plan 2018 - 2022. Washington, DC.

-2018b. Amendments to auditing standards for auditor's use of the work of specialsits. Washington, DC.

Richins, G., A. Stapleton, T. C. Stratopoulos, and C. Wong. 2017. Big data analytics: Opportunity or threat for the accounting profession? Journal of Information Systems 31 (3): 63-79.

Rose, A. M., J. M. Rose, K.-A. Sanderson, and J. C. Thibodeau. 2017. When should audit firms introduce analyses of big data into the audit process? Journal of Information Systems 31 (3): 81-99.

Rose, A. M., J. M. Rose, K.-A. Sanderson, J. C. Thibodeau, and K. Rotaru. 2019. Effects of data visualization on auditors' and jurors' judgments. Working paper.

Sarker, S., X. Xiao, T. Beaulieu, and A. S. Lee. 2018a. Learning from first-generation qualitative approaches in the IS discipline: An evolutionary view and some implications for authors and evaluators (part 1/2). Journal of the Association for Information Systems 19 (8): $752-$ 774. 
- 2018b. Learning from first-generation qualitative approaches in the IS discipline: An evolutionary view and some implications for authors and evaluators (part 2/2). Journal of the Association for Information Systems 19 (9): 909-923.

Schneider, G. P., J. Dai, D. J. Janvrin, K. Ajayi, and R. L. Raschke. 2015. Infer, predict, and assure: Accounting opportunities in data analytics. Accounting Horizons 29 (3): 719-742.

Securities and Exchange Commission. 2008. Summary report of issues identified in the commission staff's examinations of select credit rating agencies. Washington, DC.

Sinclair, N. 2015. How KPMG is using Formula 1 to transform audit. Instutue of Chartered Accountants of Scotland.

Smith, W. 2016. The HealthSouth fraud: A case of ethical malpractice. Charlotte, NC: AAA Forensic Accounting Section Midyear Research Conference.

Statistical Analysis System (SAS) Institute. 2012. Demystifying data mining.

-2014. How a hybrid anti-fraud approach could have saved government benefit programs more than $\$ 100$ million.

Sutton, S. G., J. Reinking, and V. Arnold. 2011. On the use of grounded theory as a basis for research on strategic and emerging technologies in accounting. Journal of Emerging Technologies in Accounting 8 (1): 45-63.

Sutton, S. G., R. Young, and P. McKenzie. 1995. An analysis of potential legal liability incurred through audit expert systems. Intelligent Systems in Accounting, Finance and Management 4 (3): 191-204.

Titera, W. R. 2013. Updating audit standard—Enabling audit data analysis. Journal of Information Systems 27 (1): 325-331.

Todd, P., and I. Benbasat. 1992. The use of information in decision making: An experimental investigation of the impact of computer-based decision aids. MIS Quarterly 16 (3): 373393.

Torpey, D., V. Walden, and M. Sherrod. 2009. Fraud triangle analytics: Applying Cressey's theory to e-mail communications. Fraud Magazine July/August.

-2010. Breaking the status quo in e-mail review: Fraud triangle analytics. Fraud Magazine May/June.

Triki, A., and M. M. Weisner. 2014. Lessons from the literature on the Theory of Technology Dominance: Possibilities for an extended research framework. Journal of Emerging Technologies in Accounting 11 (1): 41-69.

Trompeter, G., and A. Wright. 2010. The world has changed - Have analytical procedure practices? Contemporary Accounting Research 27 (2): 669-700.

Tuttle, B. M., and R. Kershaw. 1998. Information presentation and judgment strategy from a cognitive fit perspective. Journal of Information Systems.

Vasarhelyi, M. A., A. Kogan, and B. M. Tuttle. 2015. Big data in accounting: An overview. Accounting Horizons 29 (2): 381-396.

Venkatesh, V., M. Morris, G. Davis, and F. Davis. 2003. User acceptance of information 
technology: Toward a unified view. MIS Quarterly 27 (3): 425-478.

Vessey, I. 1991. Cognitive fit: A theory-based analysis of the graph versus tables literature. Decision Science 22 (2): 219-240.

Vessey, I., and D. Galletta. 1991. Cognitive fit: An empirical study of information acquisition. Information Systems Research 2 (1): 63-84.

Warren, J. D., K. C. Moffitt, and P. Byrnes. 2015. How big data will change accounting. Accounting Horizons 29 (2): 397-407.

Yin, R. 2009. Case study research: Design and methods. Sage Publications.

Yoon, K., L. Hoogduin, and L. Zhang. 2015. Big data as complementary audit evidence. Accounting Horizons 29 (2): 431-438. 


\section{Figure 1 \\ Graphical Depiction of Results for Bud}

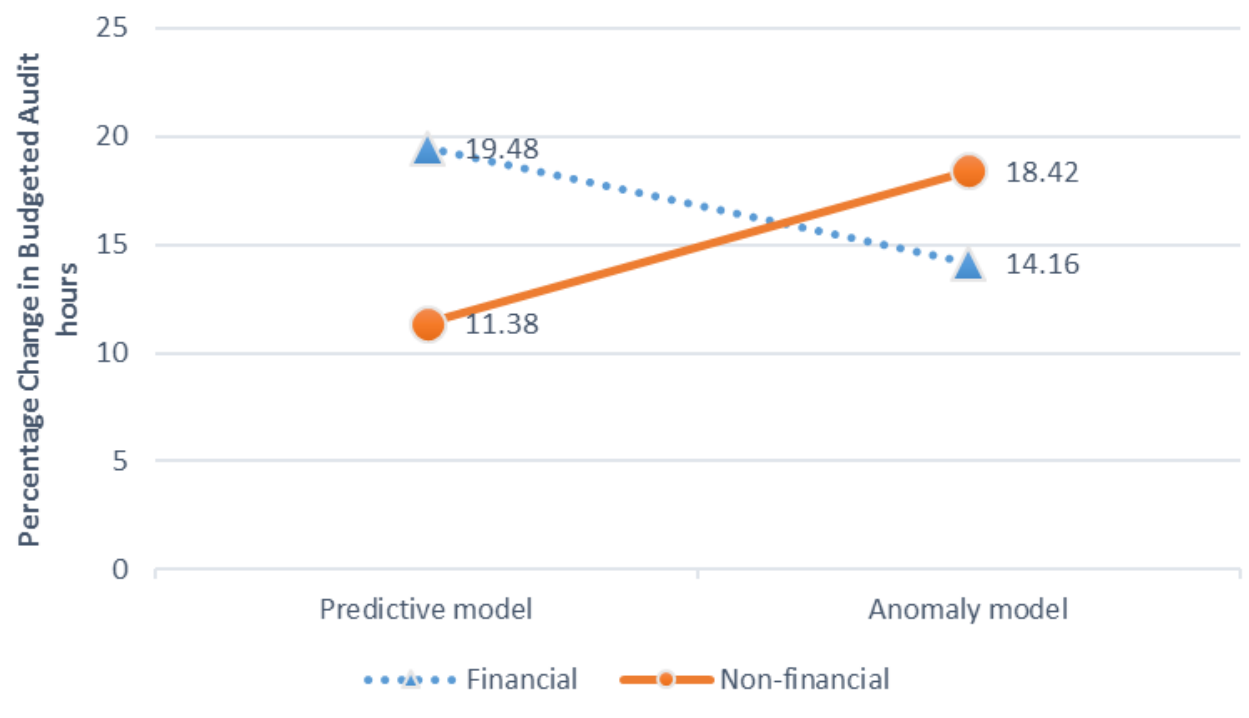

Bud measures particpants percentage change in budgeted audit hours. Participants used a slider scale ranging from $-100 \%$ to $100 \%$ to indicate their desired change in budgeted audit hours. 
Table 1

Demographic Profile of Participants (n=98)

GENDER

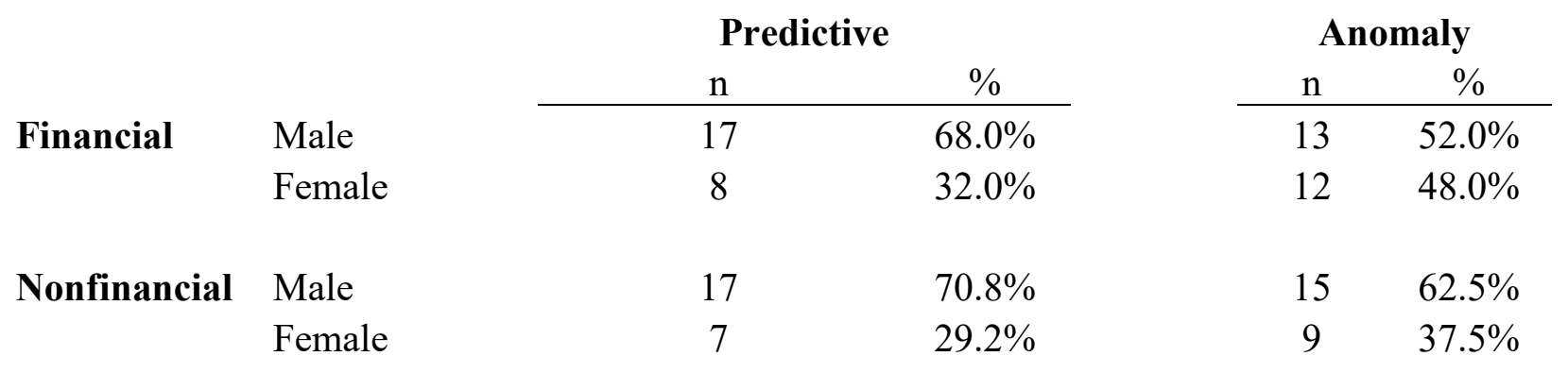

TITLE

\begin{tabular}{|c|c|c|c|c|c|}
\hline & & & & & naly \\
\hline & & $\mathrm{n}$ & $\%$ & $\mathrm{n}$ & $\%$ \\
\hline Financial & Staff & 6 & $24.0 \%$ & 6 & $24.0 \%$ \\
\hline & Senior & 7 & $28.0 \%$ & 6 & $24.0 \%$ \\
\hline & Supervisor & 1 & $4.0 \%$ & 0 & $0.0 \%$ \\
\hline & Manager & 5 & $20.0 \%$ & 6 & $24.0 \%$ \\
\hline & Director & 2 & $8.0 \%$ & 1 & $4.0 \%$ \\
\hline & Partner & 4 & $16.0 \%$ & 6 & $24.0 \%$ \\
\hline Nonfinancial & Staff & 5 & $20.8 \%$ & 5 & $20.8 \%$ \\
\hline & Senior & 8 & $33.3 \%$ & 11 & $45.8 \%$ \\
\hline & Supervisor & 3 & $12.5 \%$ & 3 & $12.5 \%$ \\
\hline & Manager & 5 & $20.8 \%$ & 3 & $12.5 \%$ \\
\hline & Director & 0 & $0.0 \%$ & 1 & $4.2 \%$ \\
\hline & Partner & 3 & $12.5 \%$ & 1 & $4.2 \%$ \\
\hline
\end{tabular}

FIRM SIZE

Financial Local

Regional

National

International

Nonfinancial Local

Regional

National

International
6

8

7

\section{Predictive}

\begin{tabular}{cc}
\multicolumn{2}{c}{ Predictive } \\
$\mathrm{n}$ & $\%$ \\
\hline 2 & $8.0 \%$ \\
11 & $44.0 \%$ \\
4 & $16.0 \%$ \\
8 & $32.0 \%$
\end{tabular}

$12.5 \%$

$25.0 \%$

$33.3 \%$

$29.2 \%$

$\begin{array}{ll}3 & 12.5 \% \\ 6 & 25.0 \% \\ 8 & 33.3 \% \\ 7 & 29.2 \%\end{array}$

Anomaly

\begin{tabular}{cc}
$\mathrm{n}$ & $\%$ \\
\hline 6 & $24.0 \%$ \\
3 & $12.0 \%$ \\
8 & $32.0 \%$ \\
8 & $32.0 \%$
\end{tabular}

$\begin{array}{cc}0 & 0.0 \% \\ 7 & 29.2 \% \\ 5 & 20.8 \% \\ 12 & 50.0 \%\end{array}$


AUDIT MANUFACTURING CLIENTS

\begin{tabular}{|c|c|c|c|c|c|}
\hline & & & & & naly \\
\hline & & $\mathrm{n}$ & $\%$ & $\mathrm{n}$ & $\%$ \\
\hline Financial & Yes & 13 & $52.0 \%$ & 13 & $52.0 \%$ \\
\hline & No & 12 & $48.0 \%$ & 12 & $48.0 \%$ \\
\hline Nonfinancial & Yes & 15 & $62.5 \%$ & 9 & $37.5 \%$ \\
\hline & No & 9 & $37.5 \%$ & 15 & $62.5 \%$ \\
\hline
\end{tabular}

\begin{tabular}{|c|c|c|c|c|c|}
\hline & & & VATEL & $\mathbf{E N}$ & \\
\hline & & & & & naly \\
\hline & & $\mathrm{n}$ & $\%$ & $\mathrm{n}$ & $\%$ \\
\hline Financial & Yes & 22 & $88.0 \%$ & 18 & $72.0 \%$ \\
\hline & No & 3 & $12.0 \%$ & 7 & $28.0 \%$ \\
\hline Nonfinancial & Yes & 22 & $91.7 \%$ & 20 & $83.3 \%$ \\
\hline & No & 2 & $8.3 \%$ & 4 & $16.7 \%$ \\
\hline
\end{tabular}

Note: More participants in the predictive-nonfinancial condition reported auditing manufacturing clients than participants in the anomaly-nonfinancial condition $(p=0.0866)$. Participants in the anomaly-financial condition reported higher titles than participants in the anomaly-nonfinancial condition $(\mathrm{p}=0.0778)$. Neither of these differences were significant when included in an ANCOVA for either dependent variable. 


\section{Table 2}

\section{Descriptive Statistics and Tests of Hypothesis Percent Increase in Budgeted Audit Hours}

Panel A - Descriptive Statistics - Change in Budgeted Audit Hours mean [standard deviation]

\begin{tabular}{|c|c|c|c|}
\hline \multirow[b]{2}{*}{ Type of Data } & \multicolumn{3}{|c|}{ Type of Model } \\
\hline & Predictive model & Anomaly model & Overall \\
\hline \multirow[t]{3}{*}{ Financial } & 19.480 & 14.160 & 16.820 \\
\hline & {$[14.021]$} & [9.616] & [12.199] \\
\hline & $n=25$ & $n=25$ & $\mathbf{n}=\mathbf{5 0}$ \\
\hline \multirow[t]{3}{*}{ Nonfinancial } & 11.375 & 18.417 & 14.896 \\
\hline & [9.458] & [11.769] & [11.146] \\
\hline & $n=24$ & $n=24$ & $n=48$ \\
\hline \multirow[t]{3}{*}{ Overall } & 15.510 & 16.245 & \\
\hline & {$[12.567]$} & [10.827] & \\
\hline & $n=49$ & $n=49$ & \\
\hline
\end{tabular}

Panel B: ANCOVA Results

Source of variation

\begin{tabular}{c} 
df \\
\hline 1 \\
1 \\
1 \\
1 \\
93
\end{tabular}

\begin{tabular}{c} 
MSE \\
\hline 2.030 \\
174.151 \\
762.480 \\
752.275 \\
122.890
\end{tabular}

\begin{tabular}{cc} 
F-Statistic & p-value \\
\cline { 1 - 1 } & \\
1.42 & 0.898 \\
6.20 & 0.237 \\
6.12 & 0.015 \\
& 0.015
\end{tabular}

Panel C: Follow-Up Tests of Simple Effects controlling for employer Size Source of variation

Effect of Type of Model on Nonfinancial Data

Effect of Type of Model on Financial Data

Effect of Type of Data on Predictive Models

\begin{tabular}{c} 
df \\
\hline 1 \\
1 \\
1 \\
1
\end{tabular}

\begin{tabular}{c} 
MSE \\
\hline 409.033 \\
353.780 \\
843.339 \\
101.252
\end{tabular}

\begin{tabular}{cc} 
F-Statistic & p-value \\
\hline 3.33 & 0.071 \\
2.88 & 0.093 \\
6.86 & 0.010 \\
0.82 & 0.366
\end{tabular}

Dependent variable is the percent change in budgeted audit hours. Participants used a slider scale ranging from $-100 \%$ to $100 \%$ to select their answer.

The Type of Model was manipulated by varying whether the participants was told the Central Data Analytics Group used Anomaly models (Type of Model=1) or Predictive models (Type of Model=0). Type of Data was manipulated by varying whether the Central Data Analytics analyzed financial data (Type of Data $=1$ ) or nonfinancial data (Type of Data $=0$ ).

Firm Size measures the size of the accounting firm the participant is employed by. Local firms are measured as 1 , regional firms as 2 , national firms 3, and international firms as 4. 


\section{Table 3}

\section{Descriptive Statistics and Tests of Hypothesis Reliance}

Panel A - Descriptive Statistics - Reliance mean [standard deviation]

\begin{tabular}{|c|c|c|c|c|}
\hline \multirow[b]{2}{*}{ Type of Data } & \multicolumn{3}{|c|}{ Type of Model } & \\
\hline & Predictive model & Anomaly model & Overall & \\
\hline \multirow[t]{3}{*}{ Financial } & 22.600 & 21.920 & 22.260 & \\
\hline & [5.635] & {$[5.515]$} & {$[5.528]$} & \\
\hline & $\mathbf{n}=\mathbf{2 5}$ & $\mathbf{n}=\mathbf{2 5}$ & $\mathbf{n}=\mathbf{5 0}$ & \\
\hline \multirow[t]{3}{*}{ Nonfinancial } & 20.333 & 20.958 & 20.646 & \\
\hline & {$[6.404]$} & {$[5.086]$} & {$[5.730]$} & \\
\hline & $n=24$ & $n=24$ & $n=48$ & \\
\hline \multirow[t]{3}{*}{ Overall } & 21.490 & 21.449 & & \\
\hline & [6.069] & {$[5.276]$} & & \\
\hline & $n=49$ & $n=49$ & & \\
\hline \multicolumn{5}{|l|}{ Panel B: ANCOVA Results } \\
\hline Source of variation & df & MSE & F-Statistic & p-value \\
\hline Type of Model & 1 & 0.019 & 0.00 & 0.981 \\
\hline Type of Data & 1 & 63.809 & 1.98 & 0.163 \\
\hline Types of Model*Type of Data & 1 & 10.427 & 0.32 & 0.571 \\
\hline Error & 94 & 32.235 & & \\
\hline
\end{tabular}

Dependent variable is the Reliance scale adapted from Hampton (2005). The reliance dependent variable is the total score of five questions answered on 7 point likert scales. These questions measure participants 1) agreement that the information identified by the data analytics represents a fraud risk, 2) confidence in the accuracy of the findings of the data analytics, 3) confidence to evaluate fraud risk without the analytics (reverse coded), 4) willingness to incorporate the findings from the analytics into their fraud risk assessment, 5 ) willingness to rely on the findings of the data analytics while assessing fraud risk. The total Reliance score may range from 5 to 35 . The means are reported in Panel A.

The Type of Model was manipulated by varying whether the participants was told the Central Data Analytics Group used Anomaly models (Type of Model=1) or Predictive models (Type of Model=0). Type of Data was manipulated by varying whether the Central Data Analytics analyzed financial data (Type of Data $=1$ ) or nonfinancial data (Type of Data $=0$ ). 